in several strains of house-fly. The Wildlife Survey Section concluded its investigations of the marsupials of New South Wales and continued its work on rabbit myxomatosis, while the Division of Fisheries and Oceanography is investigating the interaction between sunlight and chlorophyll in marine plants to enable carbon dioxide in the water to be converted into plant and animal tissue. The Division of Food Preservation and Transport continued to investigate the reaction products in browned freeze-dried apricots and peaches and completed the identification of the cationic constituents, and in a series of studies parallel with those on the 'tenderizing' of beef examined the breakdown of nucleotides in the muscle tissue. Much effort was made to improve methods for killing fluit-fly in harvested fruits, and studies designed to determine the effect of different amounts of initial oxygen in the head space of highly corrosive canned products were continued with test packs of blackcurrants in syrup.

An extensive programme of research has been undertaken to improve the use of wool as a textile fibre, using increased knowledge and understanding of the complex structure of the wool fibre and its physical and chemical properties to improve it as a textile fibre. Much attention has been directed to simplifying the conventional techniques of worsted processing, and investigations continued on the treatment of woven fabrics with casein, with the object of devising an inexpensive method of shrinkproofing using aqueous solutions. Besides studies on the extension of wool fibres and their setting at new lengths, either temporarily or permanently, research on the degradation of cellulose by fungal enzymes has been diverted from the problem of protecting tent canvas against attack by moulds and linked with research on the digestibility of pasture plants by sheep. The study of the constituents of wool-wax is now concerned chiefly with the long-chain acids of the wax and with lanosterol.

Besides the Mansfield process already noted, an outstanding success of the work of the Division of Industrial Chemistry has been the zirconium-hafnium separation process resulting from its study of the chemistry of Australia's beach sands. Work on the industrial extraction of germanium from the flue dusts of coal-burning power stations continued. Crystallographic studies were directed to the chalcogenide systems of thorium with sulphur, selenium and tellurium. A novel method was evolved of increasing the resistance of concrete products to attack by sulphate solutions. Work was commenced on some aspects of fighting bush fires, the nucleation of clouds, and the separation of the components of tar from the Lurgi process for gasifying brown coal.
The theoretical and experimental study of defects in crystals and of their implications in determining the physical and chemical properties of solids continued, as well as the search for alkaloids of possible pharma. ceutical value from the native flora, a study of root exudates and their possible significance to agriculture, and the examination of plants known or suspected to be poisonous to live-stock. Considerable progress is reported in basic studios of the chemical reactions of importance in the pressure gasification of brown coal.

The Division of Tribophysics reports major advances in the knowledge of distortions in metals produced by plastic deformation and of topology and reactivity of metal surfaces, and it appears that grain-size is important in controlling both the plastic properties of copper and its annealing characteristics. Demands on the services of the Division of Metrology are increasing, and the electrolytic condensation hygrometer developed by the Division of Physics has fulfilled its early promise, and studies of the basic physies of the crystal surface were made. Research work at very low temperatures was extended to include studies of paramagnetic resonance, and work is in progress to determine the gyromagnetic ratio of the proton. In dielectrics research the emphasis was chiefly on the effect of crystal imperfections on the dielectric properties of solids, but some work continued on liquids, and a theoretical investigation was made of problems related to superconductivity in metals.

The Division of Radiophysics is investigating the basic physical properties of semiconducting materials, and the Organization is undertaking basic studies of the physics of the atmosphere with the view of obtaining a more fundamental knowledge of the weather and the processes which control it. These include further intensive field work in the 'cool change' project, in addition to the Snowy Mountains project already noted, and towards the end of June 1957 emergency operations were commenced in an attempt to induce the maximum possible precipitation from any suitable cloud formations over general areas of the eastern States where drought conditions were beginning to be experienced. In radio astronomy, two large Mills cross-aerials were completed for the study of radio waves from beyond the solar system, and a long programme of observations of the southern part of the Milky Way at a wave-length of $21 \mathrm{~cm}$. yielded interesting results on the general structure of the Galaxy. A new crossed-grating interferometer, designed for high-resolution observations of the Sun, was completed and is in operation. Lists of staff and personnel of the council and committees of the Organization and of published papers are included in the report.

\title{
FINANCE OF SCIENTIFIC RESEARCH IN BRITAIN
}

$I^{\mathrm{N}}$ $\mathrm{N}$ opening an adjournment debate in the House of Commons on December 18 on Government aid to science in Britain, Mr. F. Willey urged the need for more wholehearted support for fundamental research and a bolder approach to science such as characterizes the National Science Foundation in the United States. He suggested that the main responsibility for fundamental research must rest with the Government, but that much other scientific research requires Government assistance in some form and that industry must be persuaded to devote more resources to research. Referring more particularly to the Department of Scientific and Industrial Research, he suggested that the appointment of a full-time chairman to the Council should be considered, and that the status and authority of the Department should be increased. Mr. Willey was disturbed about the disbandment of the Microbiological Group at the National Chemical Laboratory. Nevertheless, he paid a tribute to the work of the present Lord President of the Council, 
which was endorsed by Mr. R. Fort, who, while in general supporting Mr. Willey's views, argued that fundamental research should properly be the respons. ibility of the universities. Like Mr. Willey, he echoed some criticism of the British national organization of research which has been recently voiced in Nature, but thought that the four research councils provided a good mechanism for determining research priorities and that this pattern could be more widely applied.

In his reply for the Government, Mr. H. Nicholls, Parliamentary Secretary to the Ministry of Works, after reviewing briefly the general pattern of Government support for civil science, pointed out that in the past two years the expenditure of the Department of Scientific and Industrial Research has increased by 23 per cent, of the Medical Research Council by 34 per cent, of the Agricultural Research Council by 20 per cent, and of the Nature Conservancy by 25 per cent. He then announced that the Government has decided to repeat the experiment of financing the Department of Scientific and Industrial Research on a five-year basis. In the first quinquennium ending on March 31, 1959, total expenditure would be about $£ 36$ million; for the next quinquennium a total of $£ 61$ million is envisaged, reaching $£ 14$ million for 1967-68, excluding the contribution to the European Organization for Nuclear Research. Paying tribute to the work of the research associations, Mr. Nicholls said that the thirty-nine research associations and ten smaller organizations in the scheme employ a staff of 4,500, of whom 1,500 are of graduate status, and the 20,000 member firms cover about 50 per cent of manufacturing industry. To their expenditure of about $£ 7$ million in 1957-58 the Department of Scientific and Industrial Research contributed about $£ 1.75$ million in grants, and for the next quin. quennium this will be increased to more than $£ 2$ million.

In regard to the universities, Mr. Nicholls agreed that we should look to them mainly for fundamental research and he stressed the value of the increase of postgraduate awards by about 10 per cent in the next five years. By 1963-64, 3,800 students will be receiving grants for training and research from the Department of Scientific and Industrial Research compared with 1,900 this year, and the amount available for research in universities and similar institutions will also be increased three-fold or fourfold in the next five years. In the current year university building projects to the value of $£ 12$ million are being started; for the years $1960-63$ this will rise to $£ 15$ million a year, and technical college building projects to the value of $£ 15$ million a year had been in hand sinee the end of 1956. He had every reason to believe that the target output of 20,000 scientists and engineers a year set for the late 1960's will be achieved.

In conclusion, Mr. Nicholls said that he understood the decision of the Council for Scientific and Industrial Research with regard to the Microbiological Group at the National Chemical Laboratory was taken entirely on scientific merits and without any Ministerial intervention, which would have been entirely contrary to the spirit of the Act. The Lord President was satisfied that the Council had given extremely careful thought to the matter before giving its decision. Mr. John Hynd later referred to the outstanding $£ 130,000$ in the capital cost of constructing the Jodrell Bank radio telescope. Mr. Nicholls, in reply, pointed out that the House itself had welcomed the assurance that no voted money should be spent on covering this outstanding item. Later, in a written answer, he added that the Department of Scientific and Industrial Research had

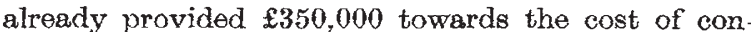
struction, and had funds at its disposal for financing research of special timeliness and promise. Any applications from the University of Manchester for grants for future research involving the use of the radio telescope would be considered on their merits, and one such grant of $£ 15,200$ had recently been offered.

\section{A RADAR SIMULATOR SYSTEM}

D URING the Second World War the training of Royal Air Force radar operators was greatly facilitated by the use of apparatus which enabled aircraft echoes to be simulated on the screen of the cathode-ray oscillograph in the radar receiver. Much ingenuity was applied to devising techniques whereby such artificial echoes could be produced and applied to the radar in such a way as to simulate the movement of a real target. By the use of the training equipment which resulted, the need to produce real echoes by flying aireraft was obviated, with consequent savings in fuel, wear and tear of aircraft and elimination of the difficulties of organization and administration.

From these war-time beginnings subsequent development of radar trainers has been considerable, as was shown by the demonstration recently given at the Farnborough works of Solartron Electronic Group, Ltd., of an elaborate installation for simulating air defence exercises and providing realistic instruction in the radar control of the interception of bomber aircraft by fighters. The equipment has been developed under the auspices of the North Atlantic Treaty Organization for use by the Italian Army.
The installation includes seven desk consoles each containing circuits for generating pulses which, when applied to the display oscillograph of a radar receiver, appear as normal aircraft echoes. Each console can simulate two aireraft. Means are provided in the consoles for moving an 'aircraft' along any desired track at speeds which may be varied between its stalling and maximum speeds. Controls are also provided for rate of turn and rate of climb, again in accordance with the capabilities of the aircraft being simulated.

All 'echoes' are displayed on a central plan position indicator from which the general state of the exercise may be studied.

The echo signals, which may be designated as originating from friendly or enemy aircraft as desired, are also displayed on the plan position indicators of a radar receiver. In so doing, the apparatus takes into account the horizontal and vertical radiation patterns, including side lobes, of the aerials of the radar being simulated. These plan position displays enable interception techniques to be practised by a controller who telephones instructions to the operator of the desk console simulating the fighter, who varies 